\title{
Logic in a Logic Way: um Aplicativo para Exercitar a Resolução de Problemas de Lógica da Olimpíada Brasileira de Informática
}

\author{
Rafael Gauna Trindade ${ }^{1}$, Cassiano Andrei Dias da Silveira Schneider ${ }^{1}$ \\ Andrea Schwertner Charão ${ }^{1}$ \\ ${ }^{1}$ Universidade Federal de SantaMaria (UFSM) \\ Santa Maria - RS - Brasil \\ \{rtrindade, cschneider, andrea\}@inf.ufsm.br
}

\begin{abstract}
Resumo. A Olimpíada Brasileira de Informática (OBI) mobiliza um grande número de alunos do país todos os anos. Na modalidade Iniciação, os competidores resolvem problemas de lógica, sem uso do computador. Visando ampliar as alternativas para preparação dos competidores nessa modalidade, desenvolveu-se o aplicativo móvel "Logic in a Logic Way", que apoia o usuário no emprego de um método sistemático de resolução de problemas textuais de lógica. Neste artigo, apresenta-se o projeto, implementação e teste do aplicativo por tutores com experiência na preparação de alunos para a OBI. Os resultados apontam possíveis melhorias para o aplicativo, que encontra-se disponibilizado com código aberto.
\end{abstract}

\begin{abstract}
The Brazilian Olympiad of Informatics (OBI) mobilizes a large number of students in the country every year. In the competition named "Initiation", the competitors solve logic problems without using the computer. In order to expand the alternatives for the preparation of the competitors in this modality, we developed "Logic in a Logic Way", a mobile application which supports the user in the use of a systematic method of solving textual problems of logic. In this article, we present the design, implementation and test of this application by tutors with experience in preparing students for OBI. The results indicate possible improvements to the application, which is available as an open source software.
\end{abstract}

\section{Introdução}

Resolver problemas de lógica, para muitas pessoas, pode não ser algo espontâneo nem simples. Esse tipo de problema é trabalhado em uma das modalidades da Olimpíada Brasileira de Informática (OBI), denominada "Iniciação", que é voltada para alunos do ensino fundamental. Muitas escolas e universidades desenvolvem atividades visando incentivar e preparar alunos para a OBI, em todas suas modalidades, enfrentando desafios inerentes a esta difícil tarefa.

Para apoiar a preparação dos competidores, a coordenação da OBI indica alguns materiais de apoio ${ }^{1}$. Na modalidade "Programação", os competidores resolvem problemas no computador e os materiais de apoio incluem diversos ambientes on-line de ensino

\footnotetext{
${ }^{1}$ Disponíveis em: http://olimpiada.ic.unicamp.br/pratique/estude
} 
de programação, com recursos variados (áudio e vídeo, correção automática, etc.). Já na modalidade Iniciação, as alternativas se reduzem a um livro sobre o tema [Martins 2011] e a alguns problemas on-line com correção automática.

Diante deste cenário, e com base na experiência dos autores na preparação de competidores para a OBI, surgiu a ideia de desenvolver um aplicativo móvel de apoio aos treinos para a modalidade Iniciação, que é mais carente de alternativas. O aplicativo, denominado "Logic in a Logic Way", inspira-se na metodologia de resolução de problemas de lógica sugerida na bibliografia básica [Martins 2011], porém mapeando-a à interface de dispositivos móveis.

O restante deste artigo está organizado como segue. Na seção 2, apresenta-se o contexto de onde surgiu o problema e a motivação para este trabalho, relacionandoo com trabalhos correlatos. Na seção 3, apresenta-se o desenvolvimento do aplicativo, elencando seus requisitos e descrevendo sua arquitetura e interface com o usuário. Na seção 4, descreve-se uma avaliação preliminar do aplicativo e, na seção 5, apresentam-se considerações finais.

\section{Contextualização}

A OBI insere-se num contexto amplo da sociedade atual que, por um lado, gera uma grande demanda por pessoas que entendam de computação e informática e que, por outro lado, enfrenta desafios para formar tais pessoas. As competições científicas, tais como a OBI, têm mobilizado muitos alunos e professores em torno de provas que, além de servirem para identificar jovens talentos, se prestam também a exercitar a compreensão e resolução de problemas.

Ao se prepararem para as provas, novos competidores e seus preparadores podem se apoiar em relatos de experiências anteriores [de Barros et al. 2009, de Almeida Machado et al. 2010, de Barros e Oeiras 2010]. Mais do que isso, a preparação requer que os competidores pratiquem a resolução de problemas e superem suas dificuldades. Nesse sentido, é desejável que existam diferentes opções para as práticas, de forma a acomodar preferências e estilos individuais.

Na próxima subseção (2.1), apresenta-se o contexto específico que motivou a criação do aplicativo, caracterizando o problema que se deseja resolver. Na subseção seguinte (2.2), discute-se trabalhos correlatos que se inserem em contextos semelhantes, porém com abordagens diferentes.

\subsection{Problema e Motivação}

A experiência que deu origem a este trabalho é um projeto de extensão da Universidade Federal de Santa Maria, que oferece capacitação para a OBI na modalidade Iniciação, a alunos de várias escolas da cidade de Santa Maria e região. A equipe do projeto é composta por discentes e professores da Universidade, que planejam e realizam treinos semanais com alunos da educação básica, durante os meses que antecedem as provas da OBI.

Como material de apoio para os treinos, são usadas as provas de OBIs passadas e slides elaborados pela equipe do projeto, com orientações sobre métodos de resolução de cada tipo de problema e exemplos resolvidos passo-a-passo. O material é disponibilizado 
em um site ${ }^{2}$. A bibliografia básica [Martins 2011] é usada como referência pelos tutores e recomendada no site mas, para o público-alvo do projeto, foi considerada pouco acessível pela linguagem utilizada, que contém muitos termos desconhecidos deste público.

Nos encontros semanais preparatórios, geralmente aos sábados e com duração de cerca de 3 horas, reserva-se alguns minutos para explanações a toda a turma e, no restante do tempo, os alunos resolvem problemas com lápis e papel e recebem orientações individualizadas dos tutores. Entre um encontro e outro, os alunos são incentivados a resolver problemas em casa e/ou na escola, mantendo contato com tutores via um grupo em rede social. Esta metodologia é semelhante à de outros projetos preparatórios para a OBI e, como se pode notar, não é muito diferente do que ocorre em aulas convencionais, que alternam teoria e prática.

Uma dificuldade observada na preparação para a OBI foi o comprometimento dos alunos com a prática frequente da resolução de problemas de lógica. De fato, poucos foram os alunos que resolveram problemas fora dos encontros com tutores. Ao se investigar os motivos disso, notou-se que os alunos percebem como "antiquada" a resolução dos problemas com lápis e papel, já que muitos são habituados a usar computador e smartphones. Embora as provas da modalidade Iniciação não usem computador, nota-se que os alunos se sentem motivados e à vontade com esse meio.

Diante disso, buscou-se opções para que os alunos pudessem diversificar suas práticas de resolução de problemas mas, conforme será detalhado na seção 2.2, não encontrou-se uma alternativa que aliasse a profundidade dos problemas de lógica da OBI à atratividade de equipamentos como smartphones e tablets. Mais do que isso, vislumbrouse a possibilidade de usar esses meios para guiar os alunos numa abordagem metódica de resolução dos problemas, tal como sugerido na bibliografia básica [Martins 2011].

\subsection{Trabalhos Correlatos}

Sistemas que focam no desenvolvimento de lógica básica, como a resolução de quebracabeças rápidos, são encontrados em plataformas web ou aplicações para dispositivos móveis (Lumosity ${ }^{3}$, Fit Brains ${ }^{4}$, Brain Challenge ${ }^{5}$, (Figura 1) etc). Entretanto eles visam somente a interpretação visual dos problemas propostos, diferentemente do aplicativo proposto que, ao se basear primariamente em problemas da Olimpíada Brasileira de Informática, visa auxiliar na resolução de problemas que necessitam uma etapa de leitura e interpretação e que não possuem recursos visuais que forneçam alguma espécie de ajuda.

É importante ressaltar que os tipos de problemas de lógica textuais que a OBI emprega mostram-se mais relevantes que desafios de lógica visuais, pois destacam o potencial para identificar alunos com vocação natural para entender e descrever procedimentos com o rigor similar àquele necessário no desenvolvimento de programas de computador [Martins 2011].

Quanto a outros trabalhos que relatam experiências de capacitação para a OBI, pode-se dizer que todos destacam a importância da prática na resolução de problemas. Há autores que incentivam essa prática por meio da realização de simulados da

\footnotetext{
${ }^{2}$ Disponível em: http://obi.inf.ufsm.br

${ }^{3}$ Lumosity (Lumosity): https://www.lumosity.com

${ }^{4}$ FitBrains (Roseta Stone Ltd.): www.fitbrains.com

${ }^{5}$ Brain Challenge (Gameloft): https://www.gameloft.com/pl/game/brain-challenge
} 
OBI [de Barros et al. 2009], promovendo um ambiente competitivo também nos treinos. Há autores que sugerem a possibilidade de transpor determinados problemas da OBI para mini-jogos de computador [de Almeida Machado et al. 2010], embora esta abordagem seja mais adaptada à modalidade Programação. Como ferramenta mediadora do aprendizado, apenas o Moodle é citado em alguns trabalhos [de Barros et al. 2009, de Barros e Oeiras 2010], como repositório de materiais e atividades e também para comunicação entre alunos e tutores.

Pode-se perceber, pela análise de trabalhos correlatos, que há um nicho pouco explorado, que pode tirar proveito da atratividade de aplicativos móveis ao utilizá-los no contexto específico de problemas de lógica da OBI, como forma de incentivar a prática de estratégias de resolução.

\section{Desenvolvimento do Aplicativo}

Uma ideia presente desde o início do desenvolvimento é que o aplicativo não deveria ser meramente um jogo no estilo quiz (somente perguntas e respostas), mas sim uma ferramenta que tornasse desnecessário o uso de papel para a resolução dos problemas, oferecendo recursos que guiassem o usuário a aplicar estratégias de resolução estudadas nos treinos.

Outra ideia presente é que o aplicativo não deveria fornecer ao usuário nenhuma ajuda explícita, sob forma de pistas ou dicas que diminuíssem o esforço de raciocínio por parte do usuário na resolução de um problema, conseguindo com isso simular em parte o ambiente encontrado nas provas da OBI.

Considerando esses princípios norteadores, foram definidos os demais requisitos do aplicativo.
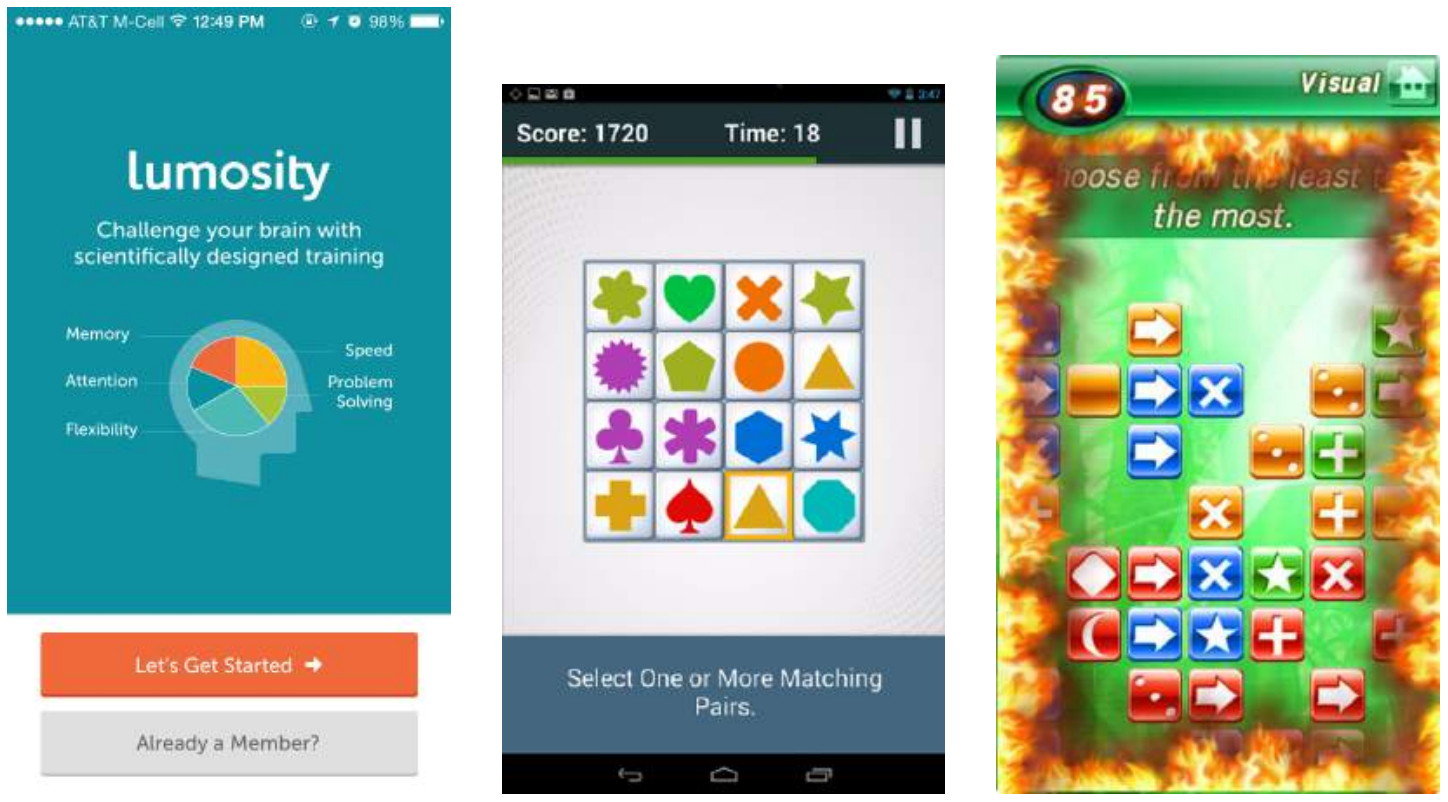

Figura 1. Capturas de tela das aplicações Lumosity, Fit Brains e Brain Challenge 


\subsection{Requisitos}

Para manter a identificação a OBI, decidiu-se que o aplicativo apresentaria os problemas de forma textual, com uma descrição do cenário e regras do problema, uma pergunta e as opções de resposta, exatamente como as provas da modalidade Iniciação. Essa apresentação, no entanto, deveria ser adaptada aos dispositivos móveis.

Para oferecer experiências com muitos problemas, surgiu a necessidade de se obter e classificar todos os dados originais dos problemas da OBI (Iniciação), sendo eles:

- Tipo dos problemas;

- Título dos problemas;

- Descrição dos problemas;

- Regras dos problemas;

- Quantidade de questões relacionadas a cada problema;

- Descrição de cada questão;

- Relação de opções de resposta para cada questão.

- Relação de respostas corretas para cada questão.

Para o armazenamento dos problemas, projetou-se um banco de dados interno de problemas e questões para a aplicação. Tal banco pode ser alimentado pela internet, quando novos problemas forem disponibilizados.

Ao interagir com o aplicativo, o usuário deve selecionar um problema, ler sua descrição (cenário e regras) e então escolher as questões relacionadas para responder. Somente ao responder todas as questões o usuário tem acesso a um botão para verificação das respostas. Durante a leitura da descrição, dois recursos estão disponíveis: "Marca Texto" e "Sistema de apoio", recursos criados para substituir o papel de rascunho para resolver os problemas. O recurso "Marca Texto" permite ao usuário selecionar e salvar qualquer parte do contexto que desejar e o "Sistema de apoio" permite manipular os elementos que estão no contexto, transformando-os em representações esquemáticas das regras lógicas para responder as questões corretamente.

Uma regra lógica, no aplicativo, consiste em um número de campos preenchidos de forma condizente com o contexto do problema. O número de campos, o valor em cada campo e seu estado 'ativo' ou 'inativo' são determinados pelo usuário. Durante a criação de uma regra lógica, pode-se escolher variáveis próprias do problema para preencher a quantia de campos desejados para tal. Essas variáveis então devem se encontrar no banco de dados da aplicação e devem serem disponibilizadas juntamente com os problemas. Visto que cada problema pode ter variáveis diferentes que o descrevam, e que não há padrões no texto para uma extração automatizada e simples das mesmas, sua extração deve ser realizada manualmente pela equipe de desenvolvimento do aplicativo.

\subsection{Arquitetura e Implementação}

O aplicativo é destinado para sistemas Android, encontrado facilmente em smartphones e tablets de baixo custo. A versão mínima da API para a qual foi projetado é a 19 (Android 4.4). Essa versão dispõe de um banco de dados local, necessário para atender aos requisitos definidos anteriormente.

Para a manutenção do banco de dados local, implementou-se um repositório de problemas on-line, com o qual a aplicação se comunica no padrão cliente-servidor. Esse 
repositório é um servidor em Django/Python, que faz uso de uma API REST minimalista para download de novos problemas. O servidor retorna arquivos no formato JSON, como ilustrado na Figura 2, dos quais a aplicação extrai os dados necessários para apresentar um problema e suas respectivas questões e armazená-lo em seu banco de dados local.

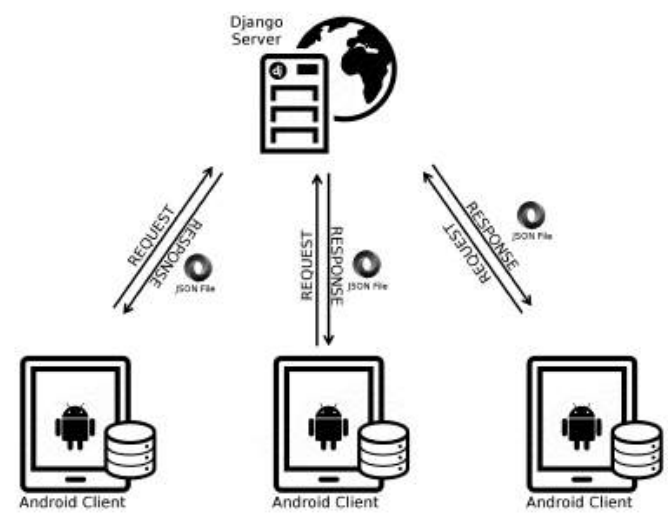

Figura 2. Arquitetura cliente-servidor empregada

\subsection{Interface com o Usuário}

Para o design da interface, optou-se pelo uso somente da API padrão do Android para interfaces de usuário. No inicio do aplicativo, é exibida a tela de carregamento, onde verifica-se a existência de novos problemas no repositório. Então o menu principal apresenta-se com quatro opções, conforme apresentado na Figura 3(b): resolver problemas, visualizar estatísticas sobre problemas resolvidos, ver um tutorial de como utilizar a aplicação e visualizar detalhes sobre os criadores da aplicação.

Ao selecionar-se a opção "Resolva", é exibida uma lista (Figura 3(c)) com todos os problemas disponíveis na aplicação. Após selecionar-se um problema, é exibida uma tela com sua descrição e uma lista enumerando as questões relacionadas.

A tela do problema é implementada como uma activity Android contendo três painéis principais, ou fragmentos (fragments Android), que o usuário pode alternar com um simples deslizar de dedo na tela:

- O fragmento com a descrição do problema, que aparece primeiro e localiza-se no meio dos outros fragmentos (Figura 4(a));

- O fragmento para criação de regras, situado à esquerda, onde o usuário pode visualizar em formato de lista as regras de lógica criadas, e tem acesso ao recurso para criação de novas regras, além da edição de regras já existentes (Figura 4(b));

- O fragmento para a listagem de conteúdo marcado, situado à direita, onde trechos da descrição podem ser exibidos separadamente, colocando-os em destaque e possibilitando uma fácil releitura (Figura 4(c)).

No fragmento da descrição, encontra-se abaixo a lista de questões relacionadas ao problema. Ao se clicar em uma questão, a lista é ocultada e dá lugar à descrição e às opções da questão selecionada (Figura 5(a)). Após respondida, uma questão é sinalizada como tal com a cor azul na lista de questões. Somente ao se responder todas as questões, um botão para conferência do resultado é apresentado (Figura 5(b)), o qual, 
quando pressionado, indica ao aplicativo que uma análise das respostas dadas seja realizada. Após analisadas as respostas, a aplicação recolore a lista de questões com duas cores: verde para questões corretamente respondidas e vermelho para as com respostas incorretas (Figura 5(c)).

O procedimento para a criação de uma marcação consiste em selecionar o trecho de texto desejado e tocar em "Marcar e lembrar" (ver Figura 6(a)). O texto destacado será

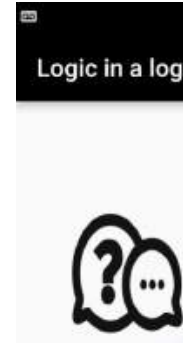

Resolva

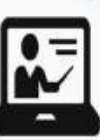

Tutorial

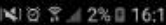

닝 $: 42 \% 016: 10$

ay

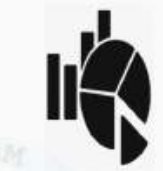

Estatisticas

(a) Tela do menu principal

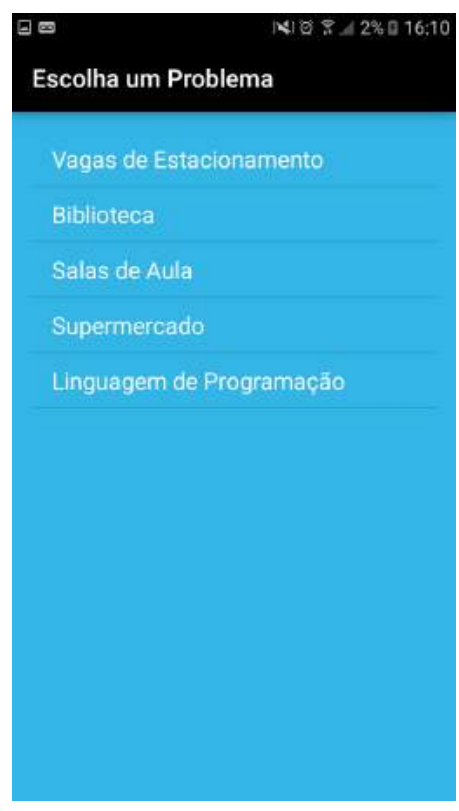

(b) Tela da lista de problemas

Figura 3. Telas apresentadas no início do aplicativo

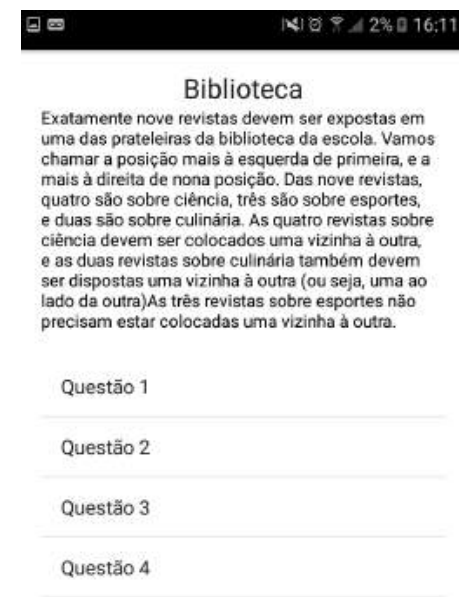

(a) Tela principal do problema

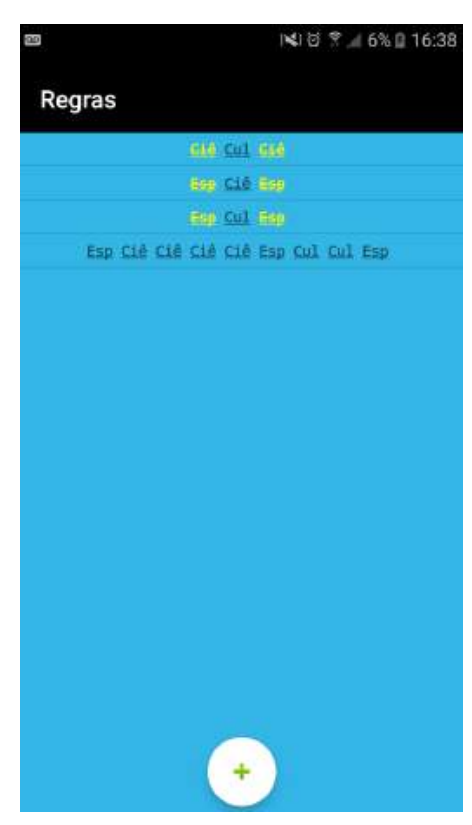

(b) Tela das regras criadas

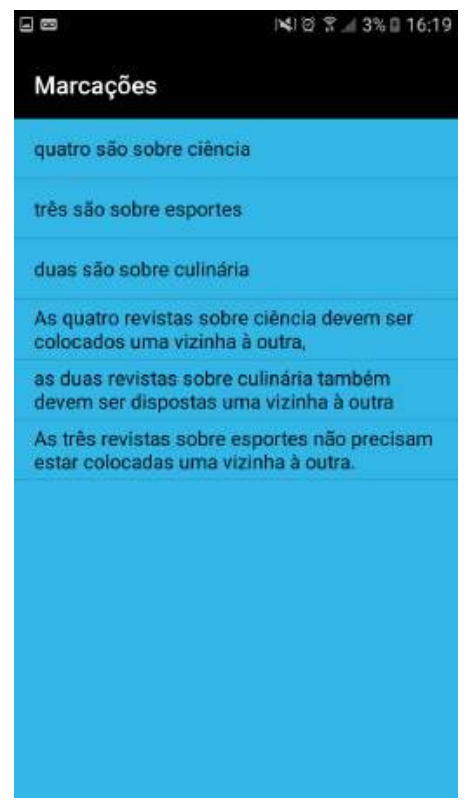

(c) Tela das marcações criadas

Figura 4. Telas com os painéis presentes na resolução de um problema 
exibido em separado no painel de marcações, como visto anteriormente na Figura 4(c). Cada marcação pode ser removida separadamente, caso seja desejado.

Para a criação de regras lógicas, um botão para adição de regras é encontrado no painel esquerdo. É exibido ao usuário um diálogo que permite escolher quantas casas uma regra terá, seja de posicionamento ou ordenação ou implicação lógica. O usuário escolhe a variável que preencherá o campo dentre as disponíveis para o problema corrente, escolhe se cada campo será negado ou não, e então cria uma regra que será exibida em lista juntamente com as outras criadas, conforme visto anteriormente na Figura 4(b). A Figura 6(b) mostra o diálogo de criação de uma regra.

\section{Testes e Resultados}

O desenvolvimento do aplicativo atingiu uma versão estável e propensa a testes no final de 2016, período em que não havia treinos para a OBI previstos no projeto. Assim, primeiramente, submeteu-se o aplicativo a testes de aceitação com tutores do projeto de extensão que, embora não sejam o principal público-alvo, também devem conhecer e utilizar este recurso. Estes tutores estavam familiarizados com estratégias de resolução usando lápis e papel.

Nestes testes, encontraram-se principalmente problemas com a adaptação da interface gráfica para diversos tamanhos de telas. Um dos desafios a ser vencido é o pouco espaço em tela para a criação de regras de muitas casas, embora esta limitação só seja percebida em alguns problemas da OBI (mais difíceis). Outro fator relacionado é o apelo visual da aplicação, que pode ter seu design gráfico melhorado.

De modo geral, a experiência com todos os recursos combinados auxiliou satisfatoriamente os tutores. A necessidade de uma folha de papel para rascunho foi sendo

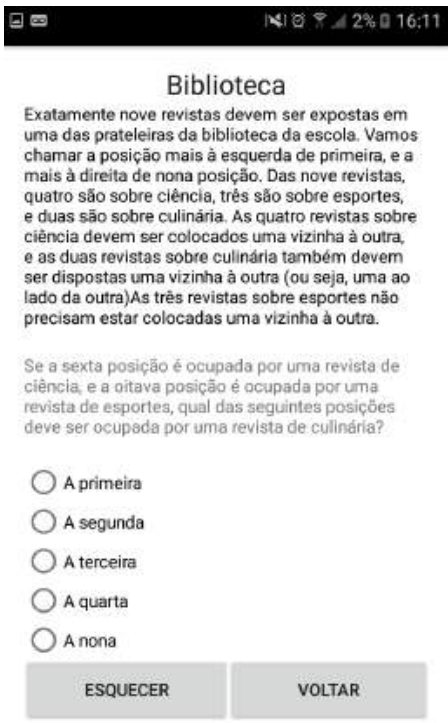

(a) Tela do problema com uma questão em primeiro plano

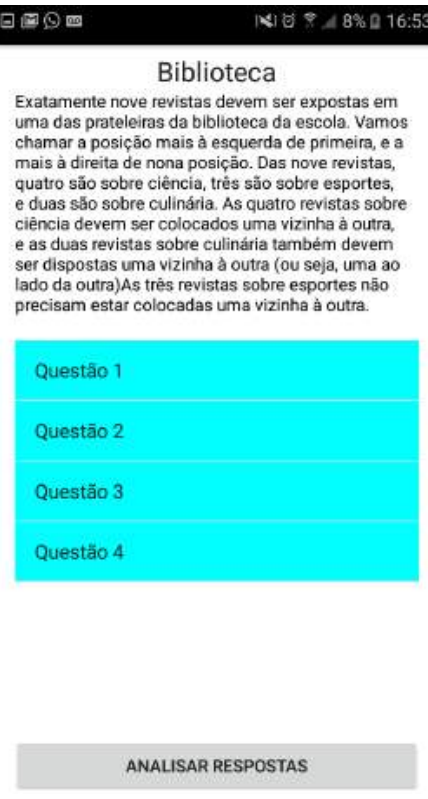

(b) Tela do problema com todas as questões respondidas e o botão de análise visível

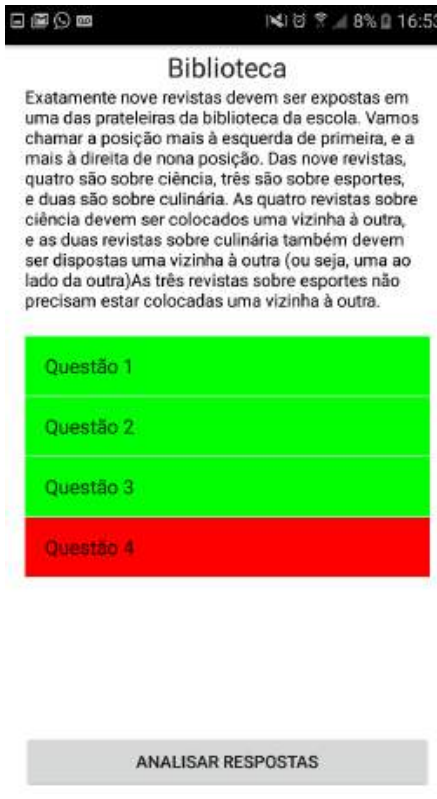

(c) Tela das respostas coloridas conforme sua corretude

Figura 5. Telas encontradas durante a resolução de um problema 
eliminada aos poucos, questão após questão, uma vez dominada a maneira mais natural de usar os recursos a favor do usuário.

\section{Conclusão e Trabalhos Futuros}

Neste trabalho, desenvolveu-se o aplicativo "Logic in a Logic Way", uma ferramenta para diversificar as práticas de resolução de problemas de lógica da OBI, na modalidade Iniciação. Utilizando tecnologias para dispositivos móveis, a ferramenta visa ser atrativa ao público, contrastando com práticas de resolução de problemas apenas com lápis e papel. O aplicativo transpõe para sua interface as mesmas estratégias de resolução utilizadas no meio analógico, apresentando-se como uma opção e não como um substituto.

O aplicativo é um software de código aberto, disponível em um repositório público ${ }^{6}$. Seu desenvolvimento ainda está em curso: novos recursos estão sendo planejados para a ferramenta, além de extensão e aprimoramento dos já existentes. Dentre eles, cabe citar:

- Suporte a novos tipos de problemas;

- Melhorias na interface gráfica;

- Recurso para a criação de anotações manuais;

- Marcação de alternativas identificadas como incorretas pelo usuário;

- Aprimorar o banco local de dados para criação do menu "Estatísticas";

- Implementar um tutorial sobre as funções do aplicativo.

Embora a primeira versão estável já tenha permitido satisfazer os requisitos elencados, ainda é necessário realizar testes com os jovens competidores durante seus treinos para a OBI. Neste sentido, pretende-se utilizar o aplicativo com alunos participantes do projeto de extensão, que se preparam para competir na OBI em 2017.

\footnotetext{
${ }^{6}$ Disponível em: https://github.com/cassiandrei/logicinalogicway
}

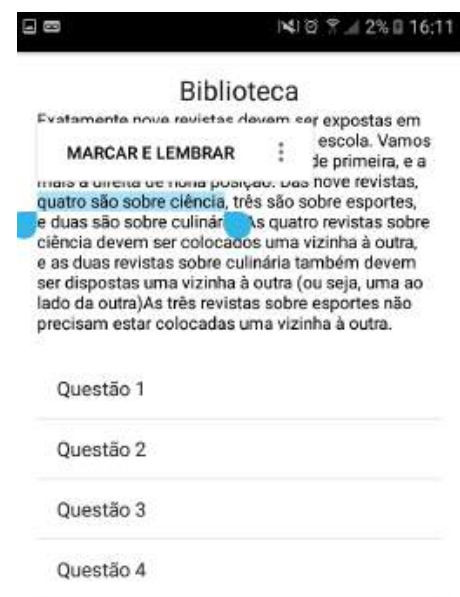

(a) Tela exibindo a criação de uma marcação

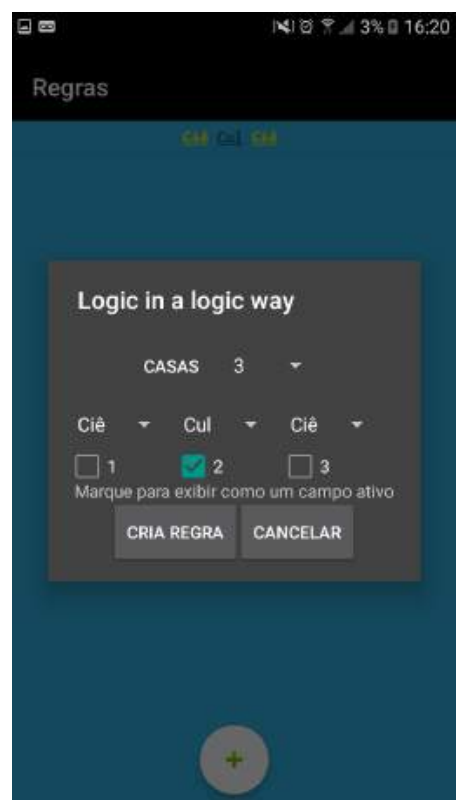

(b) Diálogo de criação de uma regra lógica

Figura 6. Telas que exibem o uso dos recursos apresentados pela aplicação 


\section{Referências}

de Almeida Machado, E. Z., Vasconcelos, I. R., Amorim, K. M., Andrade, A. M. S., Barreto, L. P., e Santos, D. A. (2010). Uma experiência em escolas de ensino médio e fundamental para a descoberta de jovens talentos em computação. In Anais do Workshop sobre Educação em Computação - (WEI), pages 798 - 807. Sociedade Brasileira de Computação.

de Barros, L. G. e Oeiras, J. Y. Y. (2010). Extensão universitária em computação por meio da olimpíada brasileira de informática. In Anais do Workshop sobre Educação em Computação - (WEI), pages 788 - 797. Sociedade Brasileira de Computação.

de Barros, L. G., Ribeiro, S. P. S., e Oeiras, J. Y. Y. (2009). Projeto de extensão universitária para apoio e realização da olimpíada brasileira de informática em escolas. In Anais do Workshop sobre Educação em Computação - (WEI), pages 567 - 576. Sociedade Brasileira de Computação.

Martins, W. S. (2011). Jogos de Lógica: Divirta-se e prepare-se para a Olimpíada Brasileira de Informática. Viera. 